\title{
PRELIMINARY RESULTS OF EURAMET ROCKWELL COMPARISON BETWEEN INRiM AND UME (EURAMET.M.H-S1.A.B.C)
}

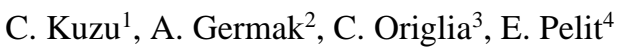 \\ ${ }^{1}$ UME, Kocaeli, Turkey, cihan.kuzu@tubitak.gov.tr \\ ${ }^{2}$ INRiM, Torino, Italy, a.germak@inrim.it \\ ${ }^{3}$ INRiM, Torino, Italy, c.origlia@inrim.it \\ ${ }^{4}$ UME, Kocaeli, Turkey, ercan.pelit@tubitak.gov.tr
}

\begin{abstract}
:
A bilateral supplementary comparison between INRiM (National Metrology Institute of Italy) and UME (National Metrology Institute of Turkey) had been decided to be organized in the field of Hardness Metrology to determine the consistency of the national hardness standards in both countries realizing Rockwell Hardness measurements in accordance with ISO 6508-1:2016 [1] and ISO 6508-3:2015 [2] standards. In this paper the procedure and preliminary measurement results of the bilateral EURAMET supplementary comparison between the two laboratories are explained.
\end{abstract}

Keywords: Hardness, Rockwell, comparison, supplementary

\section{INTRODUCTION}

A bilateral supplementary comparison between INRiM (Istituto Nazionale di Ricerca Metrologica) and UME (TÜBİTAK Ulusal Metroloji Enstitüsü) was carried out in the field of Hardness Metrology to determine the consistency of the national hardness standards used in both countries realizing Rockwell Hardness measurements in accordance with the ISO 6508-1:2016 [1] and the ISO 65083:2015 [2] standards, including the new definition of Rockwell Hardness scales accepted by the CIPM/CCM WGH [3]. The most important and the most widely used Rockwell Hardness scales such as HRA, HRBW and HRC constitute the scope of the comparison which was piloted by INRiM.

The blocks used in the comparison as transfer standards were provided by UME. Each NMI measured five hardness levels for HRC and four hardness levels for HRA and HRBW scales on the same transfer standards, using both their own and common indenters which also were provided by UME by providing its own indenters. Measurements were carried out first by UME as the provider of the blocks, then by the pilot laboratory
(PL) INRiM, then again by UME for checking the stability of the transfer standards.

The NMIs were requested to realize the traceability of each component constituting the hardness scales on their national standards to the base SI units and constitute their uncertainty budgets before the comparison measurements.

\section{TRANSFER STANDARDS USED IN THE COMPARISON}

In the bilateral comparison a total of three sets of hardness reference blocks were used; one set for each hardness scale of HRA, HRBW and HRC, separately. Five blocks for HRC scale and four blocks for each of HRA and HRBW scales, a total of 13 hardness reference blocks were used. The blocks are placed in a wooden protective case during transportation with their anti-rusting paper and original cover provided by their producer. Some information related to the hardness reference blocks used in the comparison and their pictures are given below.

Table 1: Hardness reference blocks for HRA scale

\begin{tabular}{|c|c|c|c|}
\hline No & $\begin{array}{c}\text { Hardness } \\
\text { Value }\end{array}$ & $\begin{array}{c}\text { Serial } \\
\text { Number }\end{array}$ & Producer \\
\hline $\mathbf{1}$ & 27 HRA & $668-385$ & YAMAMOTO \\
\hline $\mathbf{2}$ & 46 HRA & $666-752$ & YAMAMOTO \\
\hline $\mathbf{3}$ & 66 HRA & $293-733$ & YAMAMOTO \\
\hline $\mathbf{4}$ & 87 HRA & $284-385$ & YAMAMOTO \\
\hline
\end{tabular}

Table 2: Hardness reference blocks for HRBW scale

\begin{tabular}{|c|c|c|c|}
\hline No & $\begin{array}{c}\text { Hardness } \\
\text { Value }\end{array}$ & $\begin{array}{c}\text { Serial } \\
\text { Number }\end{array}$ & Producer \\
\hline $\mathbf{1}$ & $32 \mathrm{HRBW}$ & $668-326$ & YAMAMOTO \\
\hline $\mathbf{2}$ & $53 \mathrm{HRBW}$ & $661-029$ & YAMАMOTO \\
\hline $\mathbf{3}$ & $73 \mathrm{HRBW}$ & $666-251$ & YAMАMOTO \\
\hline $\mathbf{4}$ & $95 \mathrm{HRBW}$ & $666-850$ & YAMАMOTO \\
\hline
\end{tabular}


Table 3: Hardness reference blocks for HRC scale

\begin{tabular}{|c|c|c|c|}
\hline No & $\begin{array}{c}\text { Hardness } \\
\text { Value }\end{array}$ & $\begin{array}{c}\text { Serial } \\
\text { Number }\end{array}$ & Producer \\
\hline $\mathbf{1}$ & $25 \mathrm{HRC}$ & $492-096$ & YAMAMOTO \\
\hline $\mathbf{2}$ & $36 \mathrm{HRC}$ & $489-678$ & YAMAMOTO \\
\hline $\mathbf{3}$ & $45 \mathrm{HRC}$ & $369-719$ & YAMAMOTO \\
\hline $\mathbf{4}$ & $57 \mathrm{HRC}$ & $454-774$ & YAMAMOTO \\
\hline $\mathbf{5}$ & $67 \mathrm{HRC}$ & $486-336$ & YAMAMOTO \\
\hline
\end{tabular}

The pictures of the transfer standards used in the comparison with their nominal hardness values and serial numbers are given below. Their surfaces were cleaned with soft material before and after measurements when it is needed.
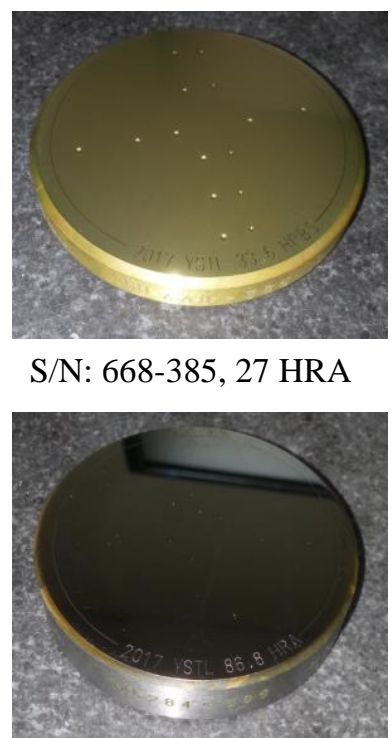

S/N: 293-733, 66 HRA
S/N: 668-385, 27 HRA

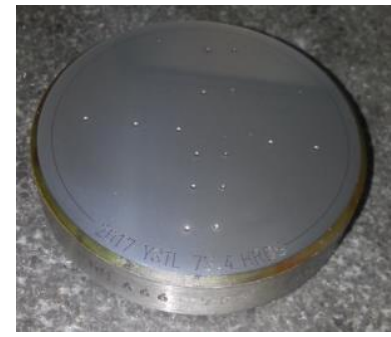

S/N: 666-752, 46 HRA

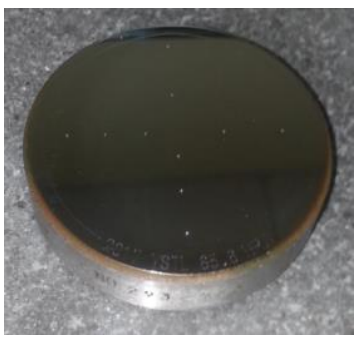

S/N: 284-385, 87 HRA
Figure 1: Transfer Standards for HRA scale
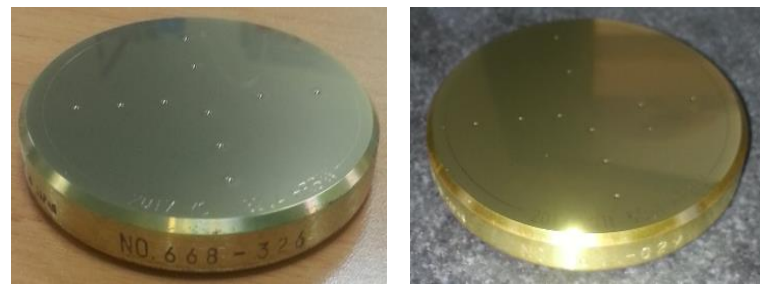

S/N: 668-326, 32 HRBW
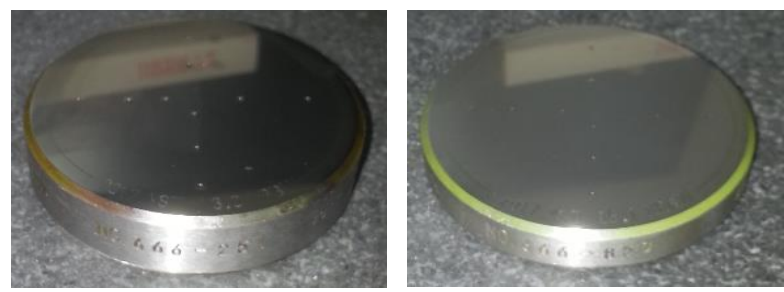

S/N: 666-251, 73 HRBW

S/N: 666-850, 95 HRBW

Figure 2: Transfer Standards for HRBW scale

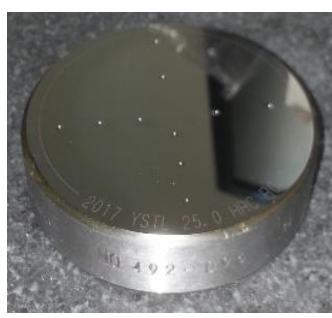

S/N: 492-096, 25 HRC

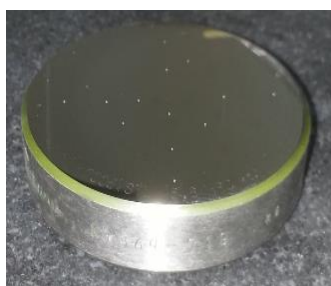

$\mathrm{S} / \mathrm{N}: 369-719,45 \mathrm{HRC}$

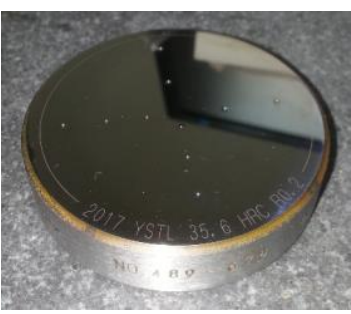

S/N: 489-678, 36 HRC

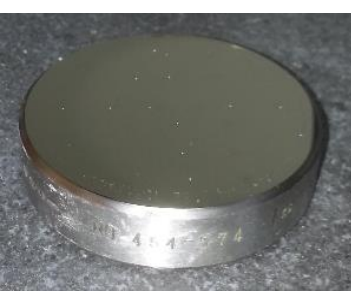

S/N: 454-774, 57 HRC

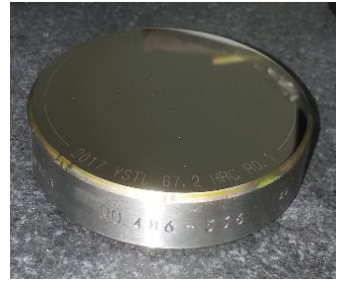

S/N: 486-336, 67 HRC

Figure 3: Transfer Standards for HRC scale

\section{COMPARISON PROCEDURE}

It was requested that each participant shall assure that the national standards to be used in the comparison at least were in accordance with the ISO 6508-1:2016 [1] and the ISO 6508-3:2015 [2] standards. Under these circumstances the components to be calibrated/verified are as follows;

- Force (preliminary load, total load, preliminary load after removal of the additional load).

- Testing cycle (in accordance with the new definition of HRC scale accepted by the CCM WGH [3] or at least in accordance with the ISO 6508-1:2016 [1] and the ISO 6508-3:2015 [2] standards).

- Indenter geometrical parameters (in accordance with the ISO 6508-3:2015 [2] standard).

- Depth measurement system (in accordance with the ISO 6508-3:2015 [2] standard).

Beside management of calibration of the components given above, the blocks were placed in the laboratory one day before the measurements for temperature equilibrium. The measurement steps realized during the comparison measurement are as follows;

- Before starting the measurements, it was assured that the standardizing machines were working properly in accordance with their design parameters and the relevant ISO standards' requirements. 
- It was assured that the anvil where the blocks are seated on and both surfaces of the reference blocks were clean.

- It was assured that the relevant scale and related indenter and other requirements were mounted/selected etc.

- The ambient temperature was recorded.

- Two sets of 7 measurements (with the two indenters, one common and one own) uniformly distributed on the surface of the block were made and recorded on the data form.

- The ambient temperature was recorded.

Seven measurements were carried out: the first two were discarded in order to eliminate the effects coming from adaptation of the machine and the blocks. In the calculations the last five indentations were taken into consideration. The first two indentations were recorded but not used in the calculations.

\section{REFERENCE VALUES OF INFLUENCE PARAMETERS}

In the calibration of hardness reference blocks the calibration laboratories realize this work in accordance with some internationally defined standards or accepted definitions. To perform measurements under the same or very similar conditions by the participants it has been significant to agree on reference values of the influence parameters and testing cycles and realize them as much as possible to have more comparable reference systems.

Table 4: Reference Values for Rockwell Hardness Scales HRA, HRBW and HRC

\begin{tabular}{|c|c|c|c|c|c|}
\hline Symbol & \multicolumn{2}{|c|}{ Test parameter } & $\begin{array}{l}\text { Reference } \\
\text { value }\end{array}$ & $\begin{array}{c}\text { Start } \\
\text { measurement }\end{array}$ & $\begin{array}{c}\text { Stop } \\
\text { measurement }\end{array}$ \\
\hline$F_{0}$ & \multicolumn{2}{|c|}{ Preliminary force } & $98.0665 \mathrm{~N}$ & - & - \\
\hline \multirow{3}{*}{$F$} & \multicolumn{2}{|c|}{ Total test force for HRA } & $588.399 \mathrm{~N}$ & - & - \\
\hline & \multicolumn{2}{|c|}{ Total test force for HRBW } & $980.665 \mathrm{~N}$ & - & - \\
\hline & \multicolumn{2}{|c|}{ Total test force for HRC } & $1470.998 \mathrm{~N}$ & - & - \\
\hline$\alpha$ & \multicolumn{2}{|c|}{$\begin{array}{c}\text { Angle of the indenter (HRA, } \\
\text { HRC) }\end{array}$} & $120^{\circ}$ & $\begin{array}{l}\text { Blend point of } \\
\text { the sphere and } \\
\text { cone }\end{array}$ & $\pm 400 \mu \mathrm{m}$ \\
\hline$D$ & \multicolumn{2}{|c|}{$\begin{array}{c}\text { Diameter of ball indenter } \\
\text { (HRBW) }\end{array}$} & $1.5875 \mathrm{~mm}$ & - & - \\
\hline$R_{a}$ & \multicolumn{2}{|c|}{$\begin{array}{l}\text { Spherical tip radius of the } \\
\text { indenter (HRA, HRC) }\end{array}$} & $200 \mu \mathrm{m}$ & $\begin{array}{l}-30^{\circ} \text { (from the } \\
\text { axis) }\end{array}$ & $\begin{array}{l}+30^{\circ} \text { (from the } \\
\text { axis) }\end{array}$ \\
\hline$V_{\text {fis }}$ & \multicolumn{2}{|c|}{$\begin{array}{l}\text { Final indentation speed of } \\
\text { additional load application }\end{array}$} & $30 \mu \mathrm{m} \cdot \mathrm{s}^{-1}$ & $\sim 80 \% \mathrm{~F}$ & $\sim 99 \% \mathrm{~F}$ \\
\hline$T_{p}$ & \begin{tabular}{|c|}
$\begin{array}{c}\text { Total time of } \\
\text { preliminary test } \\
\text { force }\end{array}$ \\
\end{tabular} & \multirow{3}{*}{$T_{p}=\frac{T_{a}}{2}+T_{p m}$} & $3 \mathrm{~s}$ & - & - \\
\hline$T_{\mathrm{a}}$ & $\begin{array}{c}\text { Application time } \\
\text { of preliminary } \\
\text { test force }\end{array}$ & & \multirow{2}{*}{ - } & $\sim 1 \% \mathrm{~F}_{0}$ & $\sim 99 \% \mathrm{~F}_{0}$ \\
\hline$T_{\mathrm{pm}}$ & $\begin{array}{c}\text { Duration time of } \\
\text { preliminary test } \\
\text { force }\end{array}$ & & & $\sim 99 \% \mathrm{~F}_{0}$ & Reading \\
\hline$T_{\mathrm{df}}$ & \multicolumn{2}{|c|}{ Duration of the total force } & $5 \mathrm{~s}$ & $\sim 99 \% \mathrm{~F}$ & $\sim 99 \% \mathrm{~F}$ \\
\hline$T_{\text {rf }}$ & \multicolumn{2}{|c|}{ Final reading time } & $4 \mathrm{~s}$ & $\sim 101 \% \mathrm{~F}_{0}$ & Reading \\
\hline$T$ & \multicolumn{2}{|c|}{ Temperature of test } & $23^{\circ} \mathrm{C}$ & $\begin{array}{l}\text { Beginning of } \\
\text { the test }\end{array}$ & $\begin{array}{l}\text { End of } \\
\text { the test }\end{array}$ \\
\hline
\end{tabular}

In this comparison the reference values were chosen according to the HRC definition decided by the CIPM/CCM WGH [3]. Deviations from these values were taken into the uncertainty calculations.
Table 4 includes the reference values and measurement cycle used in the HRA, HRBW and HRC measurements and Figure 4 shows the measurement cycle for HRA, HRBW and HRC.

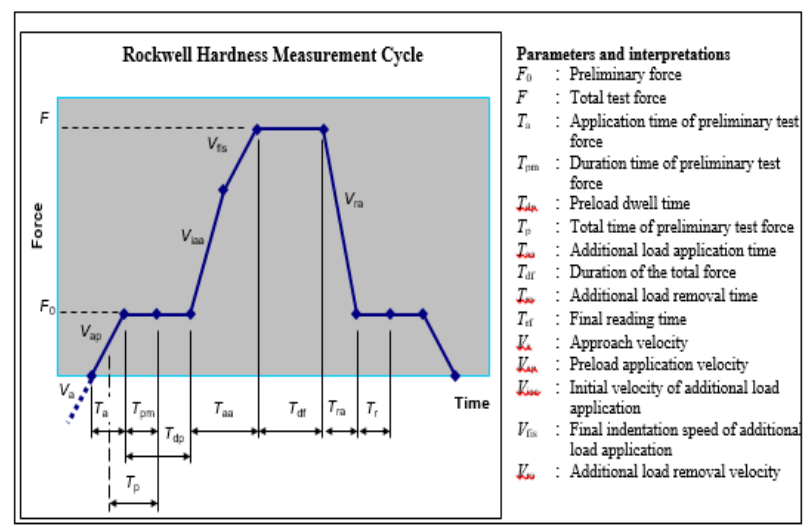

Figure 4: Identification of the HRA, HRBW and HRC Measurement Cycle [3]

\section{ELABORATION OF THE RESULTS}

As its being a supplementary comparison, there is no possibility to assign a reference value linked to an internationally accepted reference. In line with this situation, each laboratory recorded the measurement results and uncertainty values in the data sheet provided in the annex of the Technical Protocol for each hardness reference block. The pilot laboratory was responsible for collecting the measurement data from the participants, compiling, elaboration and preparing the reports. The measurement results were used to compute the Comparison Reference Value (CRV), degrees of equivalence (DoE) with the CRV and $E_{\mathrm{n}}$ ratios. The calculation is shown in following steps and made by making use of the following equations.

- Calculation of the Comparison Reference Value (CRV)

The pilot laboratory determined CRV by calculating the weighted mean of measurements of the two participants $\left(x_{r e f}\right)$ by making use of the following equation,

$$
x_{\text {ref }}=\frac{x_{1} / u^{2}\left(x_{1}\right)+\cdots+x_{n} / u^{2}\left(x_{n}\right)}{1 / u^{2}\left(x_{1}\right)+\cdots+1 / u^{2}\left(x_{n}\right)}
$$

- The uncertainty of the CRV ( $\left.x_{r e f}\right)$ was calculated by the following expression,

$$
\frac{1}{u^{2}\left(x_{r e f}\right)}=\frac{1}{u^{2}\left(x_{1}\right)}+\cdots+\frac{1}{u^{2}\left(x_{n}\right)}
$$

where,

$x_{i} \quad$ : measured value of participating institute, $i(i=1,2, \ldots, n)$

$u\left(x_{i}\right) \quad$ : standard uncertainty of $x_{i}$ 


$$
u\left(x_{r e f}\right): \text { standard uncertainty of } x_{r e f}
$$

- The deviation from the CRV is calculated by,

$$
d_{i}=x_{i}-x_{r e f}
$$

- The uncertainty of this deviation at a $95 \%$ level of confidence is,

$$
U\left(d_{i}\right)=k \cdot u\left(d_{i}\right)
$$

Where $u\left(d_{i}\right)$ is calculated by,

$$
u^{2}\left(d_{i}\right)=u^{2}\left(x_{i}\right)-u^{2}\left(x_{r e f}\right)
$$

and $k=2$.

- The coefficient $E_{\mathrm{n}}$ is the equivalence between the measurements of participating institutes, is calculated as given below,

$$
E_{n}=\frac{x_{i}-x_{r e f}}{\sqrt{U^{2}\left(x_{i}\right)-U^{2}\left(x_{r e f}\right)}}
$$

where,

$$
\begin{aligned}
& U\left(x_{i}\right)=k \cdot u\left(x_{i}\right) \\
& U\left(x_{r e f}\right)=k \cdot u\left(x_{r e f}\right)
\end{aligned}
$$

- The $x_{i}$ is equivalent with $x_{\text {ref }}(\mathrm{CRV})$ at $95 \%$ confidence level, if $\left|E_{\mathrm{n}}\right| \leq 1$,

where,

$X_{\text {INRiM }} \quad$ is INRiM measurement value,

$U_{\text {NRRM }}$ is the expanded uncertainty value that declared by INRiM,

XUME is UME measurement value,

UJME is the expanded uncertainty value that declared by UME,

$X_{\text {ref }}$ is the Comparison Reference Value (CRV),

$U_{\text {ref }}$ is the uncertainty value of $\mathrm{CRV}$,

$d_{\mathbb{N R R}} \quad$ is the deviation value of INRiM from the CRV,

$U_{\text {d-INRM }}$ is the uncertainty of the deviation value of INRiM from the CRV

$E_{\mathrm{n}-\mathrm{NNR}}$ is the degree of equivalence of INRiM expressed in $E_{\mathrm{n}}$ ratio,

dUME is the deviation value of $\mathrm{UME}$ from the CRV,

$U_{\text {d-UME }}$ is the uncertainty of the deviation value of UME from the CRV,

$E_{n-U M E} \quad$ is the degree of equivalence of $\mathrm{UME}$ expressed in $E_{n}$ ratio.

\section{COMPARISON RESULTS}

In this comparison the degree of equivalence of each participant with respect to the CRV was calculated. This calculation comprises calculation the deviation of each participant from the CRV and the associated uncertainty of this deviation. Also the $E_{\mathrm{n}}$ ratios were also calculated for each hardness scale and level. The two participants declare consistent uncertainty values and measurements

\begin{tabular}{|c|c|c|c|c|c|c|c|c|c|c|c|}
\hline$X_{\text {UME }}$ & $U_{U M E}$ & $X_{\text {INAM }}$ & $U_{\text {INRRM }}$ & $X_{\text {ref }}$ & $U_{\text {ref }}$ & $d_{\text {UME }}$ & $U_{\text {d.UME }}$ & $E_{n \cup U M E}$ & $d_{\text {INAM }}$ & $U_{\text {d-NAM }}$ & $E_{\text {n-мнам }}$ \\
\hline 26.68 & 0.29 & 26.35 & 0.30 & 26.52 & 0.21 & 0.16 & 0.21 & 0.77 & -0.16 & 0.21 & 0.77 \\
\hline 44.87 & 0.30 & 44.66 & 0.30 & 44.77 & 0.21 & 0.11 & 0.21 & 0.51 & -0.11 & 0.21 & 0.51 \\
\hline 65.65 & 0.30 & 65.53 & 0.30 & 65.59 & 0.21 & 0.06 & 0.21 & 0.28 & -0.06 & 0.21 & 0.28 \\
\hline 87.08 & 0.30 & 87.10 & 0.30 & 87.09 & 0.21 & -0.01 & 0.21 & \begin{tabular}{l|l}
0.05 \\
\end{tabular} & 0.01 & 0.21 & 0.05 \\
\hline
\end{tabular}
results are in a significant consistency with each other. Below you can see the tabular and graphical interpretation of the measurement results and calculations.
Table 5: DoE of INRiM and UME (wrt. CRV) - HRA common indenter

Table 6: DoE of INRiM and UME (wrt. CRV) - HRBW - common indenter

\begin{tabular}{|c|c|c|c|c|c|c|c|c|c|c|c|}
\hline$X_{\text {UME }}$ & $U_{\text {UME }}$ & $X_{\text {INAIM }}$ & $U_{\text {INRIM }}$ & $X_{\text {ref }}$ & $U_{\text {ref }}$ & $d_{\text {UMME }}$ & $U_{\text {d-UME }}$ & $E_{\text {nUME }}$ & $d_{\text {NAIM }}$ & $U_{\text {d-WRAM }}$ & $E_{\mathrm{D} \text {-NAM }}$ \\
\hline 26.68 & 0.29 & 26.42 & 0.31 & 26.55 & 0.21 & 0.12 & 0.20 & 0.61 & -0.14 & 0.22 & 0.61 \\
\hline 44.87 & 0.30 & 44.71 & 0.31 & \begin{tabular}{|l|l|}
44.79 \\
\end{tabular} & 0.22 & 0.08 & 0.21 & 0.39 & -0.09 & 0.22 & 0.39 \\
\hline 65.65 & 0.30 & 65.33 & 0.30 & 65.49 & 0.21 & 0.16 & 0.21 & 0.76 & -0.16 & 0.21 & 0.76 \\
\hline 87.08 & 0.30 & 86.96 & 0.30 & 87.02 & 0.21 & 0.06 & 0.21 & 0.28 & -0.06 & 0.21 & 0.28 \\
\hline
\end{tabular}

\begin{tabular}{|c|c|c|c|c|c|c|c|c|c|c|c|}
\hline$X_{\text {UME }}$ & $U_{\text {UME }}$ & $X_{\text {INRIM }}$ & $U_{\text {INRiM }}$ & $X_{\text {ref }}$ & $U_{\text {ref }}$ & $d_{\text {UME }}$ & $U_{\text {d-UME }}$ & $E_{\text {n-UME }}$ & $d_{\text {INRIM }}$ & $U_{\text {d-INRRM }}$ & $E_{\text {n-INRMM }}$ \\
\hline 31.29 & 0.43 & 30.94 & 0.42 & 31.12 & 0.30 & 0.18 & 0.30 & 0.59 & -0.17 & 0.30 & 0.59 \\
\hline 53.22 & 0.41 & 52.99 & 0.43 & 53.11 & 0.29 & 0.11 & 0.28 & 0.38 & -0.12 & 0.31 & 0.38 \\
\hline 72.62 & 0.39 & 72.74 & 0.42 & 72.68 & 0.29 & -0.06 & 0.27 & 0.22 & 0.07 & 0.31 & 0.22 \\
\hline 95.03 & 0.40 & 95.27 & 0.41 & 95.15 & 0.29 & -0.12 & 0.28 & 0.42 & 0.13 & 0.29 & 0.42 \\
\hline
\end{tabular}

Table 7: DoE of INRiM and UME (wrt. CRV) - HRC common indenter

\begin{tabular}{|c|c|c|c|c|c|c|c|c|c|c|c|}
\hline$X_{\text {UME }}$ & $U_{\text {UMME }}$ & $X_{\text {INRIM }}$ & $U_{\text {INaIM }}$ & $X_{\text {ref }}$ & $U_{\text {ref }}$ & $d_{\text {UME }}$ & $U_{\text {d.UMA }}$ & $E_{\text {nUMM }}$ & $d_{\text {INRMM }}$ & $U_{\text {d-INRIM }}$ & $E_{\text {n-MAMM }}$ \\
\hline 24.73 & 0.31 & 24.89 & 0.30 & 24.81 & 0.22 & -0.08 & 0.22 & 0.38 & 0.08 & 0.21 & 0.38 \\
\hline 35.10 & 0.28 & 35.25 & 0.30 & 35.17 & 0.20 & -0.07 & 0.19 & 0.36 & 0.08 & 0.22 & 0.36 \\
\hline 45.57 & 0.34 & 45.68 & 0.30 & 45.63 & 0.22 & -0.06 & 0.25 & 0.24 & 0.05 & 0.20 & 0.24 \\
\hline 55.63 & 0.30 & 55.66 & 0.31 & 55.64 & 0.22 & -0.01 & 0.21 & 0.07 & 0.02 & 0.22 & 0.07 \\
\hline 67.42 & 0.32 & 67.47 & 0.31 & 67.45 & 0.22 & -0.03 & 0.23 & 0.12 & 0.03 & 0.22 & 0.12 \\
\hline
\end{tabular}

Table 8: DoE of INRiM and UME (wrt. CRV) - HRA own indenter

Table 9: DoE of INRiM and UME (wrt. CRV) - HRBW - own indenter

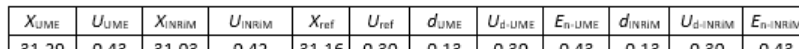
\begin{tabular}{|l|l|l|l|l|l|l|l|l|l|l|l|}
\hline 31.29 & 0.43 & 31.03 & 0.42 & 31.16 & 0.30 & 0.13 & 0.30 & 0.43 & -0.13 & 0.30 & 0.43 \\
\hline 53.22 & 0.41 & 53.3 & 0.43 & 53.26 & 0.29 & -0.05 & 0.28 & 0.17 & 0.05 & 0.31 & 0.17 \\
\hline
\end{tabular} \begin{tabular}{|l|l|l|l|l|l|l|l|l|l|l|l|}
\hline 53.22 & 0.41 & 53.32 & 0.43 & 53.26 & 0.29 & -0.05 & 0.28 & 0.17 & 0.05 & 0.31 & 0.17 \\
\hline 72.62 & 0.3 & 72.74 & 0.41 & 72.67 & 0.28 & -0.06 & 0.27 & 0.21 & 0.06 & 0.30 & 0.21 \\
\hline
\end{tabular} \begin{tabular}{|l|l|l|l|l|l|l|l|l|l|l|l|}
\hline 72.62 & 0.39 & 72.74 & 0.41 & 72.67 & 0.28 & -0.06 & 0.27 & 0.21 & 0.06 & 0.30 & 0.21 \\
\hline 95.03 & 0.40 & 5.2 & 0.41 & 9.11 & 0.29 & -0.08 & 0.28 & 0.30 & 0.09 & 0.29 & 0.30 \\
\hline
\end{tabular} \begin{tabular}{|l|l|l|l|l|l|l|l|l|l|l|l|}
\hline 95.03 & 0.40 & 95.20 & 0.41 & 95.11 & 0.29 & -0.08 & 0.28 & 0.30 & 0.09 & 0.29 & 0.30 \\
\hline
\end{tabular}

Table 10: DoE of INRiM and UME (wrt. CRV) - HRC - own indenter

\begin{tabular}{|c|c|c|c|c|c|c|c|c|c|c|c|}
\hline$X_{\text {UME }}$ & $U_{\text {UME }}$ & $X_{\text {INRIM }}$ & $U_{\text {INRIM }}$ & $X_{\text {ref }}$ & $U_{\text {ref }}$ & $d_{\text {UMmE }}$ & $U_{\text {d-UME }}$ & $E_{\text {n-UME }}$ & $d_{\text {MAIM }}$ & $U_{\text {d-ANRM }}$ & $E_{\text {n-MRAM }}$ \\
\hline 24.73 & 0.31 & 24.46 & 0.31 & 24.60 & 0.22 & 0.13 & 0.22 & 0.61 & -0.13 & 0.22 & 0.61 \\
\hline 35.10 & 0.28 & 34.85 & 0.30 & 34.98 & 0.20 & 0.12 & 0.19 & 0.63 & -0.14 & 0.22 & 0.63 \\
\hline 45.57 & 0.34 & 45.28 & 0.30 & 45.41 & 0.22 & 0.17 & 0.25 & 0.66 & -0.13 & 0.20 & 0.66 \\
\hline 55.63 & 0.30 & 55.26 & 0.30 & 55.44 & 0.21 & 0.18 & 0.21 & 0.86 & -0.18 & 0.21 & 0.86 \\
\hline 67.42 & 0.32 & 67.17 & 0.30 & 67.29 & 0.22 & 0.13 & 0.23 & 0.56 & -0.11 & 0.21 & 0.56 \\
\hline
\end{tabular}

In regard to the calculations shown in the tables above the graphical representations are as shown below.

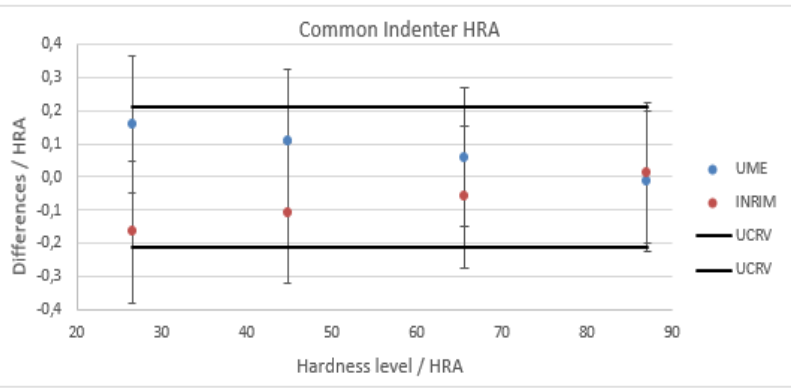

Figure 5: Deviations of INRiM and UME values from the CRV with the associated expanded uncertainty HRA - common indenter 


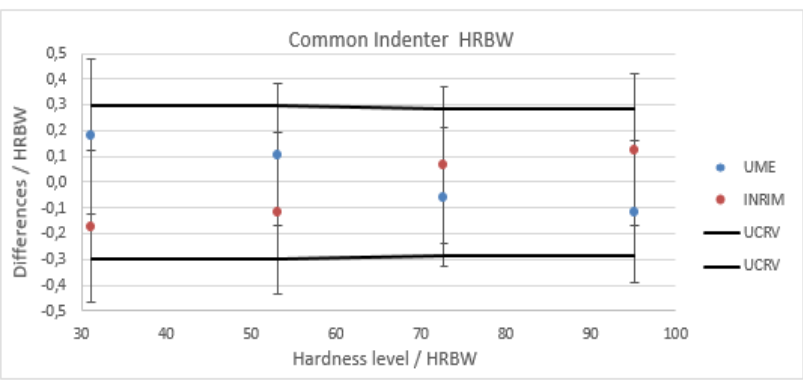

Figure 6: Deviations of INRiM and UME values from the CRV with the associated expanded uncertainty HRBW - common indenter

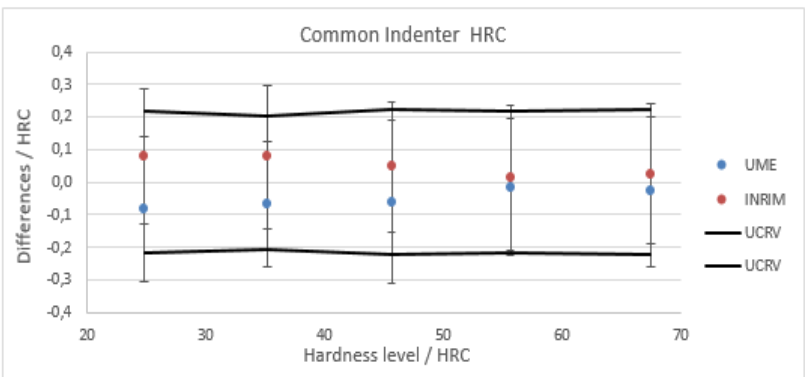

Figure 7: Deviations of INRiM and UME values from the CRV with the associated expanded uncertainty HRC - common indenter

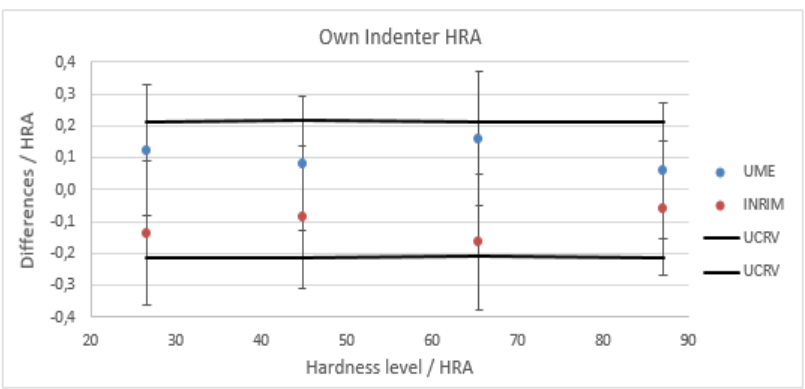

Figure 8: Deviations of INRiM and UME values from the CRV with the associated expanded uncertainty HRA - own indenter

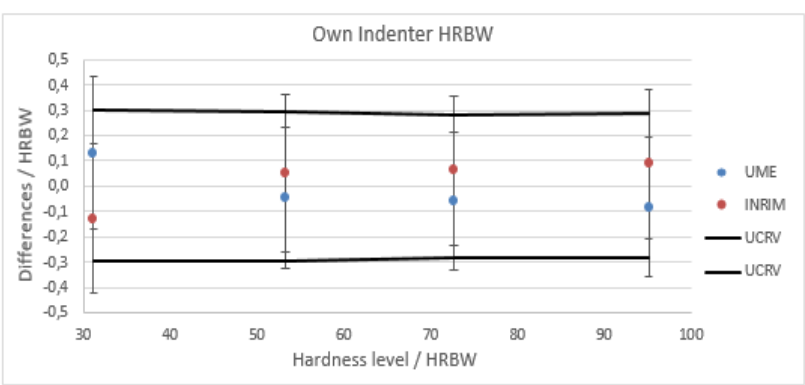

Figure 9: Deviations of INRiM and UME values from the CRV with the associated expanded uncertainty HRBW - own indenter

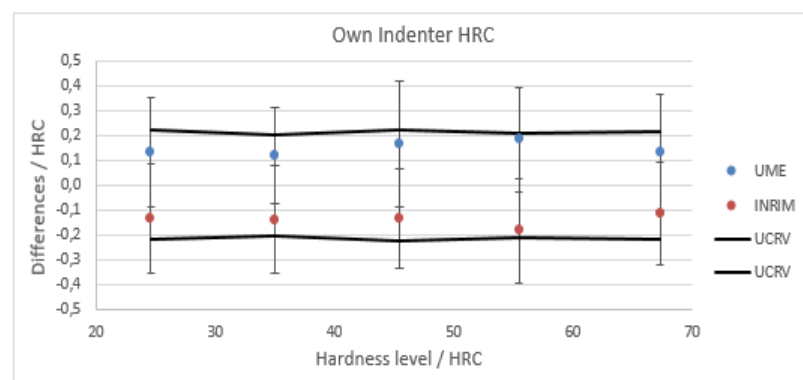

Figure 10: Deviations of INRiM and UME values from the CRV with the associated expanded uncertainty $\mathrm{HRC}$ - own indenter

\section{SUMMARY}

At the end of the bilateral comparison between INRiM and UME in the most widely used Rockwell hardness scales HRA, HRBW and HRC is completed without any unexpected phenomena in any stage of it. The participating institutes declared similar uncertainty values and there was a significant consistency between the measured values of the transfer standards. The comparison reference values (CRVs), the deviation value of INRiM and UME from the CRV and their uncertainties, $d_{\mathrm{INRiM}}, d_{\mathrm{UME}}, U_{\mathrm{d}-\mathrm{INRiM}}, U_{\mathrm{d}-\mathrm{UME}}$, and $E_{\mathrm{n}}$ ratios were calculated and shown in Tables 5 to 10 and Figures 5 to 10 in the Comparison Results. In some cases, the degrees of equivalence for the results obtained by the common indenter is greater than the degree of equivalence for the results obtained by the own indenters. This is probably because of a bias in our machine in that scale/range but still within the uncertainty declared. The degrees of equivalence show a significant consistency between INRiM and UME hardness standards in HRA, HRBW and HRC Rockwell hardness scales and this comparison is supporting the present and possible new $\mathrm{CMC}$ submissions.

\section{REFERENCES}

[1] EN ISO 6508-1:2016, Metallic Materials-Rockwell Hardness Test-Part1: Test Method (scales A, B, C, D, E, F, G, H, K, N, T).

[2] EN ISO 6508-3:2015, Metallic Materials-Rockwell Hardness Test - Part3: Calibration of Reference Blocks (scales A, B, C, D, E, F, G, H, K, N, T).

[3] https://www.bipm.org/wg/CCM/CCMWGH/Allowed/International_definitions/HRC_defi nition.pdf

[4] http://www.ltf.it/en/prodotti.php?b=3\&c=636\&p=3 $\underline{361}$

[5] EURAMET/cg-16/v.02, Guidelines on the Estimation of Uncertainty in Hardness Measurements, 2011.

[6] JCGM 100:2008, Evaluation of measurement dataGuide to the expression of uncertainty in measurement. 